\title{
Update of the management of chronic psoriasis: new approaches and emerging treatment options
}

This article was published in the following Dove Press journal:

Clinical, Cosmetic and Investigational Dermatology

30 March 2010

Number of times this article has been viewed

\section{Philip M Laws \\ Helen S Young}

The University of Manchester, Manchester Bioscience and Academic Health Sciences Centre, Department of Dermatology, Salford Royal Hospital (Hope), Manchester, UK
Correspondence: Helen SYoung

The University of Manchester, Manchester Bioscience and Academic Health Sciences Centre, Department of Dermatology, Salford Royal Hospital (Hope), Stott Lane, Salford, Manchester

M6 8HD, UK

Tel +44 I6I 2064392

Fax +44 I6I 206 I095

Email helen.s.young@manchester.ac.uk

\begin{abstract}
Psoriasis is a common, chronic inflammatory skin disease which is associated with a number of significant co-morbidities including: impairment of quality of life; cardiovascular disease; and a seronegative arthritis known as psoriatic arthritis. Our understanding of the pathogenesis of psoriasis has developed at a remarkable rate in recent years. These new insights have significantly changed our perception of the condition and have led to the development of several new treatment strategies. Biological agents have proved a major step forward in therapeutic options for psoriasis. The ability to clear, or almost clear, cutaneous disease has changed the outcomes and expectations of many patients with this disease. The impact on both physical and psychological health may be great. This review covers the clinical features and management of psoriasis with specific reference to new therapeutic options.
\end{abstract}

Keywords: psoriasis, management, biological therapy, treatment

\section{Introduction}

Understanding the pathogenesis of psoriasis has developed at a remarkable rate over the last 20-30 years. This has provided significant changes in our perception of the condition, distinctions between subtle variants, and the response to treatment.

Biological agents have proved to be a major step forward in the therapeutic options for psoriasis. The ability to clear, or almost clear, cutaneous disease has changed the outcomes and expectations of many patients with this severe disease.

This review covers the clinical features and management of psoriasis with specific reference to new therapeutic options.

\section{Clinical features of psoriasis}

Psoriasis is an immune-mediated inflammatory disease which is currently incurable and occurs in $2 \%-3 \%$ of the population of the United Kingdom (UK). ${ }^{1}$ In early-onset psoriasis, developing before the age of 40 years (Type 1 psoriasis) ${ }^{2}$ and accounting for over $75 \%$ of patients, genetic predisposition in conjunction with an environmental trigger, such as infection or stress, is important for disease expression. ${ }^{1}$

Psoriasis can be a highly disabling disease which may impact significantly on a patient's quality of life (QoL). ${ }^{3}$ Depression is significantly higher in sufferers than in the general population who have an increased incidence of suicidal ideation. ${ }^{4}$ Studies have revealed a reduction in QoL in patients with psoriasis which is comparable to patients with diabetes, heart disease and cancer. ${ }^{5}$ These factors may result in poor compliance with treatment and a further deterioration in psoriasis. 


\section{Chronic plaque psoriasis and other clinical phenotypes}

Several clinical phenotypes of psoriasis are recognized, with chronic plaque (psoriasis vulgaris) accounting for $90 \%$ of cases. ${ }^{1}$

1. In chronic plaque psoriasis well demarcated papulosquamous plaques occur in a symmetrical distribution commonly over the extensor surfaces of elbows and knees. Involvement of the scalp (typically within the hairline), lower back and umbilicus is also common. Lesions are typically red or salmon pink in color and covered by white or silver scale. The Koebner phenomenon is well recognized with psoriatic disease developing at sites of trauma or pressure. ${ }^{1}$

Other variants of the disease include inverse, guttate, pustular, and erythrodermic psoriasis.

2. Inverse psoriasis presents in a flexural distribution; the principle difference between chronic plaque and flexural psoriasis is a relative lack of scale.

3. Guttate psoriasis presents with characteristic erythematous, scaly, 'tear drop' like papules widely distributed over the body as an acute eruption in the context of Group A beta-hemolytic streptococcal infection. Guttate psoriasis is usually self limiting. Long term approximately $1 / 3$ of patients will develop chronic plaque psoriasis. ${ }^{6}$

4. Generalized pustular psoriasis (von Zumbusch psoriasis) is a rapidly progressive disease presenting with tender, sterile pustules associated with widespread erythema. The patient is unwell and clinically may have fever and lymphadenopathy. Cardiovascular compromise can ensue, particularly in those with limited cardiovascular reserve. Isolated acral pustules are characteristic of palmoplantar pustulosis and probably represents a separate disease. $^{7}$

5. Erythrodermic psoriasis can occur de novo or on a background of chronic psoriasis; patients present with erythema involving more than $90 \%$ body surface area associated with fever, malaise and systemic illness.

\section{Nail disease}

Nail changes include: pitting; oncolysis; oil drop sign; subungal hyperkeratosis; and dystrophy. Up to $50 \%$ of patients with psoriasis will demonstrate nail changes. For patients with psoriatic arthritis this figure may be as high as $80 \%{ }^{8}$

The importance of nail disease in the context of psoriatic arthritis is an area of intense research; the significance of entheseal disease appearing pivotal in disease development. ${ }^{9}$

\section{Psoriatic arthritis}

Incidence of psoriatic arthritis amongst patients with psoriasis may be as high as $25 \%,{ }^{10}$ and may pre-date the psoriatic arthritis by 12 years or more. ${ }^{11}$

Features of psoriatic arthritis include persistent joint pain, early morning stiffness, dactylitis, and enthesitis. Dactylitis is associated with progressive joint disease. ${ }^{12}$ A significant challenge in managing psoriatic arthritis is identifying the disease early, so as to reduce the risk of deformity.

Seminal work by Moll and Wright identified 5 patterns of disease: asymmetric arthritis; distal interphalangeal joint arthritis only; symmetrical arthritis - rheumatoid like and spondyloarthropathy. ${ }^{13}$ More recent work has provided clearer diagnostic criteria via the Classification Criteria for Psoriatic Arthritis (CASPAR). ${ }^{14}$

\section{Co-morbidities}

Research over recent years has highlighted that psoriasis is associated with other immune mediated inflammatory conditions including inflammatory bowel disease, and ankylosing spondylitis and cardiovascular disease. ${ }^{15-17}$

The risk of significant psoriasis-associated co-morbidities may prove a highly relevant point in rationalizing the treatment algorithm for patients with psoriasis. Reversibility of some or all of the clinical phenotypes, with systemic therapy, would demand a more aggressive approach to therapy and perhaps early intervention.

\section{Management strategies}

Treatment for psoriasis must be tailored to meet the needs of the individual based on site and severity. Traditionally a minimum body surface area (BSA) of $10 \%$ was deemed necessary to consider systemic therapy. ${ }^{18}$ This may be lower where cosmetically sensitive or functionally limiting disease is present. A minimum psoriasis area and severity index (PASI) value is frequently used in national guidelines and clinical trials (eg, PASI > 10). ${ }^{19}$

\section{Topical therapy}

For mild or moderate disease, affecting relatively small areas, a topical regimen may be sufficient to control the disease. The use of corticosteroids, vitamin D analogues, keratinolytics, tazarotene, anthracyclines and coal tar preparations have provided the topical options for treatment. New strategies for topical therapies include: 


\section{Calcipotriol and betamethasone dipropionate}

Over the last 7 years combination calcipotriol and betamethasone dipropionate have gained wide acceptance as a useful combination therapy. This has been shown to be more effective than either calcipotriol or betamethasone dipropionate alone. ${ }^{20}$ It is well tolerated as part of a 4-week cyclical regimen with calcipotriol. ${ }^{21}$

More recently the use of calcipotriol and betamethasone dipropionate in a gel formulation has proved a useful addition in treatment of scalp psoriasis. Randomized, doubleblind controlled trials have shown significant benefit from combined therapy preparations with one study reporting $92 \%$ achieving control over 52 weeks. $^{22,23}$

\section{Calcineurin inhibitors}

The role of calcineurin inhibitors is limited to facial and intertriginous disease. A study using tacrolimus $0.1 \%$ ointment to treat facial and intertriginous psoriasis of 167 patients for 8 weeks resulted in clear or almost clear in $65 \%$, as compared to $31 \%$ in the placebo group. ${ }^{24}$ Similar results were demonstrated with pimecrolimus. ${ }^{25}$ The main drawback of such treatment is burning and stinging on initiation of therapy. Cutaneous malignancy has not been observed in clinical trials. $^{26}$

\section{Ultraviolet therapy}

Where topical therapy fails to provide suitable control, or the lesions are too widely distributed for topical application, phototherapy may prove a useful adjunct. The most effective ultraviolet (UV) B wavelength for treatment (311-313 nm) has been known for more than 30 years. ${ }^{27}$ Despite this, it is only recently that delivery of narrow band UVB has been possible on a widespread basis. It is slightly less effective than psoralen (P)UVA in clinical trials although is significantly easier to deliver. ${ }^{28}$

\section{Systemic therapy}

Selection of systemic therapy is currently based on physician experience, relevant past medical history and patient choice. It is increasingly clear that psoriasis is a genetically heterogeneous group of cutaneous diseases with a similar phenotype. Clearer characterization of psoriasis phenotype, genotype, co-morbidities and the risk of adverse events from therapies should yield a clearer strategy for treatment in the future. ${ }^{29}$ Recent studies have demonstrated that early treatment of psoriatic arthritis may offer the opportunity to reduce the risk of joint deformity and progressive disability. ${ }^{30}$ Whilst this review includes baseline screening for biological therapy it should be remembered that consideration of infection and malignancy is mandatory for all systemic agents that are immunosuppressive.

\section{Methotrexate}

Generally regarded as the gold standard in managing psoriasis; methotrexate is well tolerated, efficacious, and can be used long term. It is also effective in treating psoriatic arthritis. Early clinical trials suggested that more than $60 \%$ of patients will achieve a psoriasis and area severity index (PASI) 75.31,32 More recently two comparative studies have shown significantly lower PASI 75 scores of $24 \%$ and $36 \%$ for the methotrexate arm of the study. ${ }^{33,34}$ These studies were carried out over 12 and 16 weeks respectively and may be lower due to a delayed onset of action and cautious dose incrementation.

A major limitation in therapy is liver toxicity. Historically a liver biopsy was recommended after $1.5 \mathrm{gm}$ therapy, or sooner as directed by blood monitoring. ${ }^{35}$ The monitoring of procollagen III peptide (PIIINP) has resulted in some institutions recommending liver biopsy only when persistently elevated. ${ }^{36}$ The advent of fibroscans, an ultrasound assessment of liver elasticity or stiffness, may prove a useful adjunct to PIIINP and further rationalize the use of liver biopsy. ${ }^{37}$

\section{Cyclosporine}

Cyclosporine is a widely used alternative to methotrexate, providing rapid and reliable improvement in psoriasis for up to $80 \%-90 \%$ of patients. ${ }^{38,39}$ Several further comparative studies have demonstrated a good response to treatment with PASI 75 achieved in approximately 50\%-70\%. . $^{32,33,40-42}$ Whilst highly effective the use of cyclosporine is limited by side effects including hypertension and renal impairment. Current guidelines typically recommend short course therapy for up to 12 weeks where possible. ${ }^{43}$ Despite this several studies have shown efficacy and safety with long term treatment. ${ }^{44,45}$

\section{Retinoids}

Retinoids have proved a useful alternative in the treatment of psoriasis for over 20 years. Acitretin is a useful option in managing individuals with concomitant chronic infection or malignancy given that it does not induce immunosuppression. Retinoids demonstrate efficacy in a select cohort with response rates of approximately $40 \%{ }^{46}$ Research indicates acitretin is particularly useful in erythrodermic and pustular psoriasis. $^{47}$ 
Acitretin may be combined with UV therapy, limiting the amount of UV required and reducing carcinogenic risk of phototherapy. ${ }^{48}$ A consensus conference in 2004 determined that combination therapy with acitretin and phototherapy is an underutilized therapeutic option that is both safe and effective. ${ }^{49}$ Current recommendations advise introduction of phototherapy 2 weeks after initiating acitretin. ${ }^{18}$

Studies have demonstrated that retinoids block the action of the vascular endothelial growth factor (VEGF) gene and that VEGF genotype may have a predictive role in predicting response to acitretin therapy in patients with Type 1 chronic plaque psoriasis..$^{50,51}$

\section{Fumaric acid esters}

In the UK fumaderm remains an unlicensed agent in the treatment of psoriasis. In Europe, and more particularly Germany, it has proven a highly effective alternative therapy for more than 40 years. ${ }^{52}$ It is thought to work via inhibition of nuclear factor kappa-light-chain-enhancer of activated B cells $(\mathrm{NF} \kappa \mathrm{B})$ and inducing apoptosis of T-cells. ${ }^{53}$

The main limitation to treatment is the side effect profile. The principle side effect is gastrointestinal upset, with patients reporting: nausea; vomiting; abdominal pain; diarrhea and flushing. ${ }^{54}$ This can be limited by an incremental dosing regimen over several weeks. Fumaric acid esters provide another alternative where immunosuppression is particularly contraindicated. Where tolerated, fumarates demonstrate results comparable to methotrexate and ciclosporin. ${ }^{55,56}$

\section{Biological therapies}

Biological therapy has developed at a remarkable rate with indications for a range of diseases within gastroenterology, rheumatology, dermatology, oncology and ophthalmology. Biologic agents are proteins that possess pharmacologic activity and can be extracted from animal tissue or, much more commonly, synthesized in large quantities through recombinant DNA techniques. Biologic molecules can be designed to either mimic the actions of normal human proteins or to interact with circulating proteins or cellular receptors. The following discussion covers the routinely used biological therapies and newer agents under development with reference to indication, safety, and efficacy.

\section{Indication}

The point of initiation of biological therapy will depend on local guidelines and financial constraints. As with any systemic agent, moderate to severe disease (BSA $>10 \%$, or PASI $>10$ ) or disease with high functional or cosmetic impact, would justify biological therapy.

Table I Baseline investigations prior to biological therapy and during follow up. (adapted from British Association of Dermatology Guidelines)

\begin{tabular}{lll}
\hline Investigation & Pre-treatment & Monitoring \\
\hline PASI & Yes & To assess response and 6 monthly thereafter \\
DLQI & Yes & To assess response and 6 monthly thereafter \\
Full History (Joint involvement, Chronic Infection, & Yes & At review \\
Cardiovascular status, Neurological disease, Malignancy) & & \\
FBC & Yes & 3 monthly, then 6 monthly \\
Renal profile & Yes & 3 monthly, then 6 monthly \\
Liver function tests & Yes & 3 monthly, then 6 monthly \\
Hepatitis B & Yes & Periodically in at risk groups \\
Hepatitis C & Yes & Periodically in at risk groups \\
HIV & Yes; in at risk individuals & Periodically in at risk groups \\
TB & As per BTS guidelines & Annual interferon gamma release assay \\
Autoantibodies (ANA, dsDNA) & Yes & As indicated by LFT's or other symptoms of autoimmunity \\
Urine analysis & Yes & Not routinely \\
Urine pregnancy test & Yes & Periodically in susceptible groups \\
*Chest X-ray & Yes & As clinically indicated \\
\hline
\end{tabular}

Notes: *Likely to be included in new guidelines.

Abbreviations: ANA, antinuclear antibody; dsDNA, double stranded deoxyribonucleic acid; HIV, human immunodeficiency virus; LFT, liver function test; BTS, British Thoracic Society; FBC, full blood count; TB, tuberculosis; DCQI, dermatology life quality index; PASI, psoriasis area severity index. 


\section{Baseline investigations}

Prior to commencing biological therapy a full history, examination and set of baseline investigations are required. Whilst no specific investigations have clearly been identified, the British Association of Dermatologists have issued guidance advising initial investigations to include: PASI, Dermatology Life Quality Index (DLQI); full blood count (FBC); renal profile; liver function test; antinuclear antibody; Hepatitis B and $\mathrm{C}$ serology; urine analysis and chest $\mathrm{X}$ ray as a minimum (Table 1). ${ }^{57}$ Assessment for tuberculosis is mandatory for all patients being considered for biological therapy. This will depend on the individual risk of the patient and local guidelines. Within the US a consensus statement comprehensively reviews this issue. ${ }^{58}$

Biological therapies are usually avoided through pregnancy although small studies to date have not revealed significant problems. ${ }^{19}$ Current guidelines indicate withdrawal of biological therapy preoperatively so as to minimize the risk of surgical infection and post-operative complication. ${ }^{57}$ Timing of this withdrawal should be $4-5$ half-lives prior to surgical intervention. ${ }^{59}$

Immunization is generally advised prior to commencing treatment. The use of live vaccines (varicella, mumps, measles, rubella, oral typhoid and yellow fever) and live attenuated vaccines (intranasal influenza and herpes zoster) should be avoided once therapy is commenced. ${ }^{60,61}$ Work on immune responses to patients receiving biological therapy suggests that an adequate, albeit reduced, response is observed. ${ }^{62,63}$ This has become particularly pertinent in light of the current swine flu pandemic.

\section{Tumor necrosis factor (TNF) $\alpha$ antagonists}

By far the most well characterized group of biological therapies are the TNF $\alpha$ antagonists (etanercept, adalimumab and infliximab). TNF $\alpha$ is an inflammatory cytokine produced by numerous cells including T cells and keratinocytes. TNF $\alpha$ is cleaved from a transmembrane bound precursor, from where it binds a TNF $\alpha$ receptor. The binding of TNF $\alpha$ to its receptor results in downstream activation of the inflammatory cascade via NFKB. Blockade of this pathway results in down regulation of the inflammation with marked clinical improvement.

\section{Etanercept}

A recombinant human $\mathrm{TNF} \alpha$ receptor protein (p75) fused with the Fc portion of $\operatorname{IgG1}$, etanercept binds both soluble and membrane bound TNF $\alpha .{ }^{64}$ Etanercept is efficacious in treating psoriasis and psoriatic arthritis. Phase III trials employing two treatment arms, $25 \mathrm{mg}$ twice weekly and $50 \mathrm{mg}$ twice weekly, showed a PASI 75 of $34 \%$ and $48 \%$ respectively at week $12 .{ }^{65-67}$ Etanercept has a slow onset of action and therapeutic benefit may be observed beyond this 12 week time point. ${ }^{67}$ The impact of etanercept on QoL is also demonstrated in reduced scores of depression. ${ }^{68}$ Whilst continuous therapy achieves greater efficacy at 24 weeks than interrupted therapy ( $71 \%$ versus $59 \%$ ), interrupted therapy remains a well described and effective option in managing chronic plaque psoriasis. ${ }^{66}$

Combination therapy: Concomitant $25 \mathrm{mg}$ etanercept once weekly and acitretin $(0.4 \mathrm{mg} / \mathrm{kg})$ was shown to be as effective as etanercept $25 \mathrm{mg}$ twice weekly in a small study $(\mathrm{n}=60) .{ }^{69}$ Another small study $(\mathrm{n}=59)$ of patients established on methotrexate, although not achieving a satisfactory control, were further treated with etanercept $(25 \mathrm{mg}$ twice weekly). Comparison was then made between continuous methotrexate versus gradual withdrawal of methotrexate. This showed a Physicians' Global Assessment of clear, or almost clear, in $67 \%$ and $37 \%$ for the "etanercept with continuous methotrexate" compared to "etanercept and withdrawal of the methotrexate" groups respectively. ${ }^{70}$ Whilst combination therapy with methotrexate and etanercept is established in rheumatoid arthritis evidence to support its use in psoriasis requires further research. ${ }^{71,72}$

Etanercept has been shown to be effective and safe in children aged 4-17 years of age. ${ }^{73}$ PASI 75 was achieved in $57 \%$ of patients treated with etanercept $0.8 \mathrm{mg} / \mathrm{kg}$ after 12 weeks. ${ }^{73}$

The choice of regimen employed ( $25 \mathrm{mg}$ or $50 \mathrm{mg}$ twice weekly) will be dictated by disease severity, patient weight and funding agreements. Other considerations may be in the context of chronic infections where minimal effective immunosuppression may be desirable.

Clinical practice in rheumatological disease differs in the use of etanercept, with regular concomitant methotrexate therapy. There is a small body of evidence indicating that this may reduce treatment failure rates in patients with psoriasis. ${ }^{70}$

\section{Infliximab}

A murine and human chimeric antibody, infliximab binds avidly to soluble, bound and transmembrane TNF $\alpha$. It is useful in the treatment of psoriasis and psoriatic arthritis. A phase III trial, the European Infliximab for Psoriasis Efficacy and Safety Study (EXPRESS), of infliximab at a dose of $5 \mathrm{mg} / \mathrm{kg}$ at 0,2 and 6 weeks followed by 8 week maintenance therapy achieved PASI 75 in $82 \%$ of patients at week $24 .{ }^{74}$ 
Response to treatment is remarkable with clinical improvement within 2 weeks of treatment induction. The efficacy of infliximab drops off in a subgroup of patients, at 1 year when approximately $61 \%$ of patients achieve PASI $75 .^{74,75}$ Maintaining response to therapy would appear to correlate with a detectable trough serum infliximab level ${ }^{74}$ Studies suggest that greater numbers of patients achieve PAS175 when receiving continuous treatment compared with intermittent therapy. ${ }^{75}$ This improvement in clinical symptoms translates into an improved quality of life. ${ }^{76}$ Furthermore, treatment with infliximab has been shown to improve productivity and work attendance. ${ }^{77}$

Management of nail involvement is a challenging aspect of psoriasis. The EXPRESS study demonstrated a 56\% improvement in nail psoriasis severity index (NAPSI) when treated with infliximab. ${ }^{74}$ It is recommended that infliximab be initiated as per the EXPRESS study $(5 \mathrm{mg} / \mathrm{kg}$ at week 0,2 and 6) and then maintained on an 8 weekly infusion regimen.

\section{Adalimumab}

A fully humanized monoclonal antibody directed against TNF $\alpha$, adalimumab binds both soluble and membranebound forms. It is used in the treatment of both psoriasis and psoriatic arthritis. A phase III trial of adalimumab, given initially as an $80 \mathrm{mg}$ subcutaneous dose followed by $40 \mathrm{mg}$ the following week and then every other week thereafter, achieved a PASI 75 of $71 \%$ at 16 weeks. ${ }^{78}$ Further trials, including the phase III Comparative Study of Adalimumab versus Methotrexate versus Placebo in Psoriasis Patients (CHAMPION) study, have revealed similar levels of efficacy. ${ }^{34,79}$ The improvement in clinical disease has been shown to be accompanied by significant improvement in health related QoL; comparable to that of the background population. ${ }^{80}$

Similar to other TNF $\alpha$ antagonists, adalimumab is maintained long term. Stopping treatment can result in reduced efficacy when restarted. ${ }^{78}$ It is recommended that adalimumab be initiated as per the CHAMPION study at $80 \mathrm{mg}$ week 0 , followed by $40 \mathrm{mg}$ week 1 and every other week thereafter.

\section{Complications of anti-TNF $\alpha$ therapy}

The TNF $\alpha$ antagonists are generally well tolerated. A review of relevant studies demonstrated monthly withdrawal rates due to adverse events of $0.4 \%$ for etanercept, $1.3 \%$ for infliximab, and $0.3 \%$ for adalimumab. 81 monthly serious adverse incidents were noted in $0.6 \%$ for etanercept, $1.1 \%$ for infliximab and $0.5 \%$ for adalimumab. ${ }^{81}$ However, there are a number of well recognized complications and side effects associated with TNF $\alpha$ antagonist therapy.

Adverse events following injection/infusion: These are relatively common, tend to be self-limiting, although rarely require cessation of treatment. Adverse events following injection occur in approximately 14\% for etanercept and 3\% for adalimumab whilst infusion reactions were observed in $3 \%$ for infliximab. ${ }^{74,78,82} \mathrm{~A}$ recent review paper provides a useful guide to managing such reactions. ${ }^{83}$

\section{Infection}

TNF $\alpha$ antagonists act on a central component of the inflammatory cascade and form an integral part of host defense against infection. Clinical studies indicate a modest increase in upper respiratory and cutaneous infection. More serious infections are rare although there are several case reports of opportunistic infections in such patients, including histoplasmosis and listerosis. ${ }^{84,85}$ These have largely been in the context of rheumatological disease treated with several immunosuppressive agents. In the context of serious or active infection biological therapy should be withheld.

Patients who have chronic infection require careful evaluation on a case by case basis, weighing up potential benefits and pitfalls of treatment. Hepatitis $\mathrm{C}$ is unusual in that hepatic damage is driven by cytotoxic $\mathrm{T}$ cell injury with associated high levels of TNF $\alpha$. Consequently, TNF $\alpha$ antagonists have been used in limited numbers of patients without serious complication. ${ }^{86}$ By contrast, hepatitis B viral replication is controlled by $\mathrm{TNF} \alpha$. TNF $\alpha$ antagonists have the potential for reactivation of latent hepatitis $B$ and hepatic injury. ${ }^{87} \mathrm{~A}$ review of hepatitis B management, with reference to immunosuppression, has been issued by the American Association for the Study of Liver Disease. ${ }^{88}$ A recent review of 8 patients with inactive Hepatitis $B$ treated with a TNF $\alpha$ antagonist suggest that prophylactic antiviral therapy is indicated even where ALT/AST levels are normal. ${ }^{89}$ All cases of biological therapy in the context of chronic infection should be jointly managed with input from a relevant specialist.

\section{Tuberculosis (TB)}

Tuberculosis (TB) is a well recognized complication of TNF $\alpha$ antagonist therapy. This probably represents both new infection and reactivation of latent TB. TNF $\alpha$ plays a central role in granuloma formation and inhibition of this cytokine has the clear potential for granuloma breakdown, disseminating mycobacterial infection. ${ }^{90}$ This risk may be more pronounced with monoclonal antibodies to TNF $\alpha$ (adalimumab and 
infliximab) over etanercept. The development of TB in the context of such patients has seen a significantly greater proportion of atypical infection. ${ }^{91,92}$ A high index of suspicion is therefore required with all patients being treated with biological therapy given the combination of immunosuppression and atypical disease.

Prior to initiating therapy individuals should be assessed for possible latent TB. Assessment guidelines are variable depending on country of practice. The role of tuberculin tests and interferon gamma release assay remain contentious due to their sensitivity and specificity in the context of immunosuppression. This issue has been comprehensively addressed via a US consensus statement. ${ }^{58}$

\section{Human immunodeficiency virus (HIV)}

Human immunodeficiency virus (HIV) and biological therapy should be considered with extreme caution. The safety of treating HIV positive patients is unknown but given that both have immunosuppressive effects the risks of adverse outcomes may be considerable. Despite this, there are case reports of TNF $\alpha$ antagonist therapy in rheumatological disease in patients who are HIV positive without significant problems developing. ${ }^{93}$

\section{Neurological diseases}

TNF $\alpha$ antagonists are associated with development or worsening of demyelinating disorders, notably multiple sclerosis (MS). ${ }^{19}$ A personal medical history or first degree relative affected by $\mathrm{MS}$ is a contraindication to treatment with TNF $\alpha$ antagonists. Withdrawal of the TNF $\alpha$ antagonist may result in resolution of neurological disease in the event of symptoms suggestive of demyelination. In all such cases specialist neurological opinion is advised.

\section{Heart disease}

The use of biological therapy in the context of inflammatory disease has shown conflicting data with improved cardiovascular function in some studies whilst worsening in others. A review of 47 case reports of heart failure whilst using biological therapy provides some evidence of a causative link. ${ }^{94}$ Conflicting with this review, clinical trials of TNF $\alpha$ antagonists in the context of rheumatoid arthritis have failed to identify this risk. ${ }^{95}$ Patient selection excluded known heart failure and therefore by definition has a selection bias.

Due to the concern over TNF $\alpha$ antagonists in the context of heart failure it is recommended that treatment be avoided in patients with New York Heart Association cardiac failure Class III or IV (breathless at rest or minimal exertion). ${ }^{19}$

\section{Drug-induced lupus}

Following treatment with the TNF $\alpha$ antagonists has been reported in several case studies to date. ${ }^{96}$ This has been observed in a small number of cases and is frequently reversible. There are case reports of therapeutic benefits in patients with lupus treated with a biological therapy. ${ }^{97}$

\section{Malignancy}

Early analysis of TNF $\alpha$ antagonists in managing rheumatoid arthritis identified an 11.5 fold risk of lymphoma. ${ }^{98,99}$ Subsequent inclusion in a larger registry resulted in no such relative risk identified. ${ }^{99}$ These studies failed to identify a risk of solid organ malignancy. In contrast to this a meta-analysis of 9 clinical trials involving TNF $\alpha$ antagonists identified an odds ratio for malignancy of 3.3. ${ }^{100}$ The risk was greater with high dose treatment. A subsequent review of 6 national registries has not identified a significant risk of lymphoma or solid organ malignancy amongst patients treated with TNF $\alpha$ antagonists. ${ }^{101}$

A recent systematic review of thirty six randomized controlled trial (RCTs) revealed that $26 \%$ of cancer diagnoses in the treatment arm occurred within the first 12 weeks of therapy and raise a significant question as to baseline screening. ${ }^{102}$ These results require further evaluation; data registries will help address this.

The risk of cutaneous malignancy remains an area requiring further study. A study of 1,442 patients with rheumatoid arthritis treated with etanercept failed to establish a link with squamous cell carcinoma whilst in a larger study of 13,001 patients with rheumatoid arthritis, $49 \%$ of which were exposed to a biological therapy, indicated a modest increased rate of both melanoma and non-melanoma skin cancer. ${ }^{103,104}$

\section{Alefacept}

Alefacept, used widely in the United States (US), has no European license for the treatment of psoriasis. Consisting of the extracellular cluster of differentiation (CD)-2 binding portion of lymphocyte function associated antigen-3 (LFA-3), linked to the Fc portion of human immunoglobulin (Ig) G1, its mode of action is thought to be mediated by selective depletion of memory effector (CD45RO+) T lymphocytes. ${ }^{105}$ Phase III trials of alefacept given weekly at a dose of $15 \mathrm{mg} / \mathrm{kg}$ demonstrated PASI 75 in $21 \%$ of patients at week 14. ${ }^{106-108}$

Alefacept therapy necessitates CD4 lymphocyte count prior to commencing therapy and every other week thereafter. 
Treatment should be withheld when CD4 counts drop below 250 cells/mL. Due to the impact on CD4 count, HIV and high risk of malignancy or infection exclude alefacept as an option for therapy in such patients. Whilst not routinely used to manage psoriatic arthritis limited data indicates it is effective. ${ }^{109}$

Alefacept has generally been well tolerated in clinical trials. Adverse events following injection are reported, particularly chills, which are self limiting and did not necessitate withdrawal of therapy.

\section{Efalizumab}

Efalizumab is included in this section given its proven role in treating psoriasis despite its global withdrawal. It is a recombinant monoclonal IgG1 antibody directed against the CD11a subunit of LFA-1. LFA-1 is central to T-cell adhesion and migration through endothelial wall and into inflamed skin. ${ }^{10,111}$ It is also involved in reactivation of T cells. ${ }^{112}$ Phase III trials, including the Clinical Experience Acquired with Raptiva (CLEAR) study, revealed a PASI 75 response of up to $39 \% .{ }^{113-117}$ Efalizumab is not effective in treating psoriatic arthritis. ${ }^{118}$

Due to case reports of progressive multifocal leukoencephalopathy (PML) in three patients receiving efalizumab for chronic plaque psoriasis this treatment option has been withdrawn globally. ${ }^{119}$ This complication of impaired immune surveillance is not unique to efalizumab. Natalizumab, a very late antigen (VLA)-4 antagonist, used in treating multiple sclerosis, has also been reported in association with PML. Both efalizumab and natalizumab affect $\mathrm{T}$ cell migration which is thought to underlie the susceptibility to PML. ${ }^{120}$

\section{Ustekinumab}

Interleukin (IL) 12 and IL23 share an homologous subunit, p40. Ustekinumab is an IL12/23 monoclonal antibody directed against this shared p40 subunit. IL12 is a key cytokine directing the differentiation of $\mathrm{T}$ cells into a $\mathrm{T}$ helper lymphocyte (Th)-1 phenotype. ${ }^{121}$ IL23, a member of the IL12 family, stimulates naïve T cell differentiation toward a Th17 phenotype. ${ }^{122}$ IL12/IL23 has a central role in the adaptive response involved in the pathogenesis of psoriasis. ${ }^{123}$

Phase III clinical trials for ustekinumab, including PHOENIX I and II, demonstrated $67 \%$ and $72 \%$ achieve a PASI 75 after 12 weeks with either $45 \mathrm{mg}$ or $90 \mathrm{mg}$ respectively. ${ }^{124-126}$ Ongoing improvement may be seen up to 24 weeks after commencing treatment.
The injection was well tolerated with serious adverse events in $4 \%$ compared to $1 \%$ for the placebo group. It is also effective in treating psoriatic arthritis. ${ }^{127}$ As an upstream inhibitor of TNF $\alpha$ it may be expected that the risk profile of ustekinumab may be broadly similar.

\section{Data registry}

Biological therapies are an emerging treatment option for a range of disease in dermatology. Safety profiles to date have been promising with relatively few serious adverse outcomes. However, concerns remain over the long term safety of these agents. With pharmacovigilance a high priority, several countries including: France; Italy; Spain; Sweden; Germany, and the United Kingdom have established data registry's. The British Society of Rheumatology Biologics Register (BSRBR) have recently reported initial results which to date have identified a modest rise in cutaneous infection; ${ }^{128}$ a reduced risk of myocardial infarction; ${ }^{129}$ but no major increased risk of fetal abnormality or spontaneous abortion in patients with rheumatoid arthritis treated with TNF $\alpha$ antagonists. ${ }^{130}$ Caution must be exercised in extrapolating data from this register since the underlying disease may influence outcomes.

\section{The future of psoriasis and biological therapies}

As our understanding of the immunopathogenesis of psoriasis grows so does the opportunity for development of new therapeutic targets. New and emerging options for biological therapy include the TNF $\alpha$ blocking monoclonal antibodies (certolizumab and golumimab) and targets of the IL-12/23 pathway (ABT-874). In addition to the development of new biological therapies a number of small molecules show promise of delivering new therapeutic options in managing psoriasis.

\section{Certoluzimab-pegol}

This fragment antigen binding $\left(\mathrm{F}_{\mathrm{ab}}\right)$ portion of human TNF $\alpha$ has been shown to be effective in the treatment of Crohn's disease and rheumatoid arthritis; and may therefore prove efficacious in the treatment of psoriasis. ${ }^{131}$ Due to the absence of the fragment crystallizable ( $\mathrm{Fc}$ ) region, activation of complement and antibody-dependent cell mediated cytotoxicity does not occur in-vitro. ${ }^{132}$

\section{Golimumab}

A phase III trial of golimumab treated for psoriatic arthritis given $50 \mathrm{mg}$ monthly in a placebo controlled study involving 405 patients indicated $40 \%$ of patients achieve a PASI 
75 at 14 weeks. ${ }^{133}$ Care must be used in interpreting this data since pre-intervention PASI scores are likely to be lower, and hence less sensitive, than patients entering clinical trials for cutaneous disease only. The Golimumab-Randomized Evaluation of Safety and Efficacy in Subjects with Psoriatic Arthritis Using a Human Anti-TNF Monoclonal Antibody (GO-REVEAL) study demonstrated a similar efficacy in treating psoriatic arthritis.

\section{Briakinumab}

Briakinumab, previously known as ABT-874, is a p40 monoclonal antibody, with a similar mechanistic action to ustekinumab. Phase 2 trials of briakinumab, involving 180 patients, were randomized to 6 different treatment arms. After 12 weeks, PASI 75 was achieved in $63 \%$ to $93 \%$, depending on which treatment arm was being reviewed. ${ }^{134}$

\section{Fezakinumab}

IL 22 is a key cytokine produced by Th17 cells which has been shown to induce dermal inflammation and acanthosis. ${ }^{135}$ This provides a link between adaptive immunity and epithelial dysfunction. ${ }^{136}$ Fezakinumab is a monoclonal antibody directed against IL 22 which has registered to undergo phase I clinical trials.

\section{AIN-457}

IL 17, an integral part of the psoriatic inflammatory cascade, has recently been linked to successful treatment with etanercept. ${ }^{137}$ The specificity of IL-17 inhibition raises the possibility of it providing a further therapeutic target in managing psoriasis. ${ }^{137}$ Current work on a phase II clinical trial in psoriatic arthritis is likely to provide evidence of potential therapeutic benefit in cutaneous disease.

\section{Small molecules}

Small molecules are a diverse group of organic compounds which by definition have a low molecular weight. An ever increasing number of molecules have registered patents. These have been recently reviewed. ${ }^{138}$ Most of these drugs act on an intracellular target and modify intracellular signaling. Some examples are reviewed below.

\section{Voclosporin}

Cyclosporin provides reliable and effective treatment for psoriasis. The limitations of treatment, namely nephrotoxicity and hypertension, frequently limit use. A newly developed calcineurin inhibitor, voclosporin, recently underwent phase 3 clinical trials. PASI 75 was achieved at 12 weeks in $16 \%$,
$25 \%$ and $47 \%$ for the $0.2 \mathrm{mg} / \mathrm{kg}, 0.3 \mathrm{mg} / \mathrm{kg}$ and $0.4 \mathrm{mg} / \mathrm{kg}$ groups respectively. ${ }^{139}$ This study emphasized a strong correlation with serum drug concentration, raising the possibility of enhanced efficacy and reduced toxicity.

\section{Janus kinase (JAK) 3 inhibitors}

Janus kinase (JAK) 3 inhibitors are signal transducers and activators of transduction (STAT) inhibitors. JAK3 is a protein tyrosine kinase which forms a key intracellular signal transduction point for a proinflammatory signal from $\gamma$-chain receptors, relevant to cytokines IL-2, -4, -7, -9, -15 and $-21 .{ }^{140}$ Activation of JAK3 leads to phosphorylation of STAT which then translocates to the nucleus where it modifies gene transcription. ${ }^{141} \mathrm{CP}$ 690,550 is an oral JAK3 inhibitor which has recently entered phase II clinical trials and has shown significant improvement in psoriatic plaque severity. ${ }^{142}$ Further studies with CP-690,550 are ongoing.

\section{Conclusions}

Psoriasis is a common disease which carries a significant physical and psychological burden. The impact of the disease is that it not only affects the patient but has implications on health economics. Understanding and treatment for psoriasis and psoriatic arthritis has moved forward greatly over the last few years. The identification of subtle differences in psoriasis phenotypes, pathogenesis and immunobiology will drive forward our understanding of disease and will provide new options to control the disease.

\section{Disclosures}

The authors report no conflicts of interest relavant to this research.

\section{References}

1. Griffiths CE, Barker JN. Pathogenesis and clinical features of psoriasis. Lancet. 2007;370:263-271.

2. Henseler T, Christophers E. Psoriasis of early and late onset: characterization of two types of psoriasis vulgaris. $J$ Am Acad Dermatol. $1985 ; 13: 450-456$

3. de Korte J, Sprangers MA, Mombers FM, et al. Quality of life in patients with psoriasis: a systematic literature review. J Investig Dermatol Symp Proc. 2004;9:40-47.

4. Gupta MA, Gupta AK. Depression and suicidal ideation in dermatology patients with acne, alopecia areata, atopic dermatitis and psoriasis. Br J Dermatol. 1998;139:846-850.

5. Rapp SR, Feldman SR, Exum ML, et al. Psoriasis causes as much disability as other major medical diseases. $J$ Am Acad Dermatol. 1999;41:401-407.

6. Martin BA, Chalmers RJ, Telfer NR. How great is the risk of further psoriasis following a single episode of acute guttate psoriasis? Arch Dermatol. 1996;132:717-718. 
7. Asumalahti K, Ameen M, Suomela S, et al. Genetic analysis of PSORS1 distinguishes guttate psoriasis and palmoplantar pustulosis. J Invest Dermatol. 2003;120:627-632.

8. Cohen MR, Reda DJ, Clegg DO. Baseline relationships between psoriasis and psoriatic arthritis: analysis of 221 patients with active psoriatic arthritis. Department of Veterans Affairs Cooperative Study Group on Seronegative Spondyloarthropathies. J Rheumatol. 1999;26: $1752-1756$

9. McGonagle D, Benjamin M, Tan AL. The pathogenesis of psoriatic arthritis and associated nail disease: not autoimmune after all? Curr Opin Rheumatol. 2009;21:340-347.

10. Zachariae H. Prevalence of joint disease in patients with psoriasis: implications for therapy. Am J Clin Dermatol. 2003;4:441-447.

11. Gottlieb AB, Mease PJ, Mark Jackson J, et al. Clinical characteristics of psoriatic arthritis and psoriasis in dermatologists' offices. J Dermatolog Treat. 2006;17:279-287.

12. Brockbank JE, Stein M, Schentag CT, et al. Dactylitis in psoriatic arthritis: a marker for disease severity? Ann Rheum Dis. 2005;64:88-90.

13. Moll JM, Wright V. Psoriatic arthritis. Semin Arthritis Rheum. 1973;3:55-78.

14. Taylor W, Gladman D, Helliwell P, et al. Classification criteria for psoriatic arthritis: development of new criteria from a large international study. Arthritis Rheum. 2006;54:2665-2673.

15. Najarian DJ, Gottlieb AB. Connections between psoriasis and Crohn's disease. J Am Acad Dermatol. 2003;48:805-821.

16. Brophy S, Taylor G, Blake D, et al. The interrelationship between sex, susceptibility factors, and outcome in ankylosing spondylitis and its associated disorders including inflammatory bowel disease, psoriasis, and iritis. J Rheumatol. 2003;30:2054-2058.

17. McDonald CJ, Calabresi P. Psoriasis and occlusive vascular disease. Br J Dermatol. 1978;99:469-475.

18. Menter A, Korman NJ, Elmets CA, et al. Guidelines of care for the management of psoriasis and psoriatic arthritis: section 4. Guidelines of care for the management and treatment of psoriasis with traditional systemic agents. J Am Acad Dermatol. 2009;61:451-85.

19. Menter A, Gottlieb A, Feldman SR, et al. Guidelines of care for the management of psoriasis and psoriatic arthritis: Section 1. Overview of psoriasis and guidelines of care for the treatment of psoriasis with biologics. J Am Acad Dermatol. 2008;58:826-850.

20. Kaufmann R, Bibby AJ, Bissonnette R, et al. A new calcipotriol/betamethasone dipropionate formulation (Daivobet) is an effective once-daily treatment for psoriasis vulgaris. Dermatology. 2002;205:389-393.

21. Kragballe K, Austad J, Barnes L, et al. A 52-week randomized safety study of a calcipotriol/betamethasone dipropionate two-compound product (Dovobet/Daivobet/Taclonex) in the treatment of psoriasis vulgaris. Br J Dermatol. 2006;154:1155-1160.

22. Luger TA, Cambazard F, Larsen FG, et al. A study of the safety and efficacy of calcipotriol and betamethasone dipropionate scalp formulation in the long-term management of scalp psoriasis. Dermatology. 2008;217:321-328

23. Jemec GB, Ganslandt C, Ortonne JP, et al. A new scalp formulation of calcipotriene plus betamethasone compared with its active ingredients and the vehicle in the treatment of scalp psoriasis: a randomized, doubleblind, controlled trial. J Am Acad Dermatol. 2008;59:455-463.

24. Lebwohl M, Freeman AK, Chapman MS et al. Tacrolimus ointment is effective for facial and intertriginous psoriasis. $J$ Am Acad Dermatol. 2004;51:723-730.

25. Gribetz C, Ling M, Lebwohl M, et al. Pimecrolimus cream $1 \%$ in the treatment of intertriginous psoriasis: a double-blind, randomized study. J Am Acad Dermatol. 2004;51:731-738.

26. Berger TG, Duvic M, Van Voorhees AS et al. The use of topical calcineurin inhibitors in dermatology: safety concerns. Report of the American Academy of Dermatology Association Task Force. $J$ Am Acad Dermatol. 2006;54:818-823.

27. Tham SN, Gange RW, Parrish JA. Ultraviolet-B treatment of psoriasis in patients with concomitant vitiligo. Arch Dermatol. 1987;123: 26-27.
28. Yones SS, Palmer RA, Garibaldinos TT, et al. Randomized doubleblind trial of the treatment of chronic plaque psoriasis:efficacy of psoralen-UV-A therapy vs narrowband UV-B therapy. Arch Dermatol. 2006;142:836-842.

29. Griffiths CE, Christophers E, Barker JN, et al. A classification of psoriasis vulgaris according to phenotype. Br J Dermatol. 2007; $156: 258-262$.

30. Gladman DD. Psoriatic arthritis. Dermatol Ther. 2009;22:40-55.

31. Sandhu K, Kaur I, Kumar B, et al. Efficacy and safety of cyclosporine versus methotrexate in severe psoriasis:a study from north India. J Dermatol. 2003;30:458-463.

32. Heydendael VM, Spuls PI, Opmeer BC, et al. Methotrexate versus cyclosporine in moderate-to-severe chronic plaque psoriasis. $N$ Engl J Med. 2003;349:658-665.

33. Flytstrom I, Stenberg B, Svensson A, et al. Methotrexate vs. ciclosporin in psoriasis:effectiveness, quality of life and safety. A randomized controlled trial. Br J Dermatol. 2008;158:116-121.

34. Saurat JH, Stingl G, Dubertret L, et al. Efficacy and safety results from the randomized controlled comparative study of adalimumab vs methotrexate vs placebo in patients with psoriasis (CHAMPION). Br J Dermatol. 2008;158:558-566.

35. Roenigk HH, Jr., Auerbach R, Maibach H, et al. Methotrexate in psoriasis:consensus conference. J Am Acad Dermatol. 1998;38: $478-485$.

36. Chalmers RJ, Kirby B, Smith A, et al. Replacement of routine liver biopsy by procollagen III aminopeptide for monitoring patients with psoriasis receiving long-term methotrexate:a multicentre audit and health economic analysis. Br J Dermatol. 2005;152: 444-450.

37. Berends MA, Snoek J, de Jong EM, et al. Biochemical and biophysical assessment of MTX-induced liver fibrosis in psoriasis patients:Fibrotest predicts the presence and Fibroscan predicts the absence of significant liver fibrosis. Liver Int. 2007;27:639-645.

38. Ho VC, Griffiths CE, Berth-Jones J, et al. Intermittent short courses of cyclosporine microemulsion for the long-term management of psoriasis: a. 2-year cohort study. J Am Acad Dermatol. 2001;44:643-651.

39. Ho VC, Griffiths CE, Albrecht G, et al. Intermittent short courses of cyclosporin $(\operatorname{Neoral}(\mathrm{R}))$ for psoriasis unresponsive to topical therapy: a. 1-year multicentre, randomized study. The PISCES Study Group. Br J Dermatol. 1999;141:283-291.

40. Koo J. A randomized, double-blind study comparing the efficacy, safety and optimal dose of two formulations of cyclosporin, Neoral and Sandimmun, in patients with severe psoriasis. OLP302 Study Group. Br J Dermatol. 1998;139:88-95.

41. Thaci D, Brautigam M, Kaufmann R, et al. Body-weight-independent dosing of cyclosporine micro-emulsion and three times weekly maintenance regimen in severe psoriasis. A randomised study. Dermatology. 2002;205:383-388.

42. Reitamo S, Spuls P, Sassolas B, et al. Efficacy of sirolimus (rapamycin) administered concomitantly with a subtherapeutic dose of cyclosporin in the treatment of severe psoriasis:a randomized controlled trial. $\mathrm{Br} \mathrm{J}$ Dermatol. 2001;145:438-445.

43. Griffiths CE, Dubertret L, Ellis CN, et al. Ciclosporin in psoriasis clinical practice:an international consensus statement. Br J Dermatol. 2004;150 Suppl 67:11-23.

44. Shupack J, Abel E, Bauer E, et al. Cyclosporine as maintenance therapy in patients with severe psoriasis. J Am Acad Dermatol. 1997;36: 423-432.

45. Mrowietz U, Farber L, Henneicke-von Zepelin HH, et al. Long-term maintenance therapy with cyclosporine and posttreatment survey in severe psoriasis:results of a multicenter study. German Multicenter Study. J Am Acad Dermatol. 1995;33:470-475.

46. Lowe NJ, Prystowsky JH, Bourget T, et al. Acitretin plus UVB therapy for psoriasis. Comparisons with placebo plus UVB and acitretin alone. J Am Acad Dermatol. 1991;24:591-594.

47. Van Zander J, Orlow SJ. Efficacy and safety of oral retinoids in psoriasis. Expert Opin Drug Saf. 2005;4:129-138. 
48. Tanew A, Guggenbichler A, Honigsmann H, et al. Photochemotherapy for severe psoriasis without or in combination with acitretin: a randomized, double-blind comparison study. J Am Acad Dermatol. 1991;25:682-684.

49. Lebwohl M, Drake L, Menter A, et al. Consensus conference:acitretin in combination with UVB or PUVA in the treatment of psoriasis. $\mathrm{J} \mathrm{Am}$ Acad Dermatol. 2001;45:544-553.

50. Young HS, Summers AM, Read IR, et al. Interaction between genetic control of vascular endothelial growth factor production and retinoid responsiveness in psoriasis. J Invest Dermatol. 2006;126: 453-459.

51. Diaz BV, Lenoir MC, Ladoux A, et al. Regulation of vascular endothelial growth factor expression in human keratinocytes by retinoids J Biol Chem. 2000;275:642-650.

52. Schweckendiek W. [Treatment of psoriasis vulgaris.]. Med Monatsschr. 1959;13:103-4.

53. Treumer F, Zhu K, Glaser R, et al. Dimethylfumarate is a potent inducer of apoptosis in human T cells. $J$ Invest Dermatol. 2003;121:1383-1388.

54. Hoefnagel JJ, Thio HB, Willemze R, et al. Long-term safety aspects of systemic therapy with fumaric acid esters in severe psoriasis. Br J Dermatol. 2003;149:363-369.

55. Mrowietz U, Christophers E, Altmeyer P. Treatment of psoriasis with fumaric acid esters:results of a prospective multicentre study. German Multicentre Study. Br J Dermatol. 1998;138:456-460.

56. Harries MJ, Chalmers RJ, Griffiths CE. Fumaric acid esters for severe psoriasis:a retrospective review of 58 cases. $\mathrm{Br} J$ Dermatol. 2005;153:549-551.

57. Smith CH, Anstey AV, Barker JN, et al. British Association of Dermatologists guidelines for use of biological interventions in psoriasis 2005. Br J Dermatol. 2005;153:486-497.

58. Lebwohl M, Bagel J, Gelfand JM, et al. From the Medical Board of the National Psoriasis Foundation:monitoring and vaccinations in patients treated with biologics for psoriasis. J Am Acad Dermatol. 2008;58:94-105.

59. Smith CH, Anstey AV, Barker JN, et al. British Association of Dermatologists' guidelines for biologic interventions for psoriasis. 2009. Br J Dermatol. 2009;161:987-1019.

60. Avery RK. Vaccination of the immunosuppressed adult patient with rheumatologic disease. Rheum Dis Clin North Am. 1999;25:567-584.

61. Avery RK. Immunizations in adult immunocompromised patients:which to use and which to avoid. Cleve Clin J Med. 2001;68:337-348.

62. Fomin I, Caspi D, Levy V, et al. Vaccination against influenza in rheumatoid arthritis:the effect of disease modifying drugs, including TNF alpha blockers. Ann Rheum Dis. 2006;65:191-194.

63. Kapetanovic MC, Saxne T, Nilsson JA, et al. Influenza vaccination as model for testing immune modulation induced by anti-TNF and methotrexate therapy in rheumatoid arthritis patients. Rheumatology (Oxford). 2007;46:608-611.

64. Yamauchi PS, Gindi V, Lowe NJ. The treatment of psoriasis and psoriatic arthritis with etanercept:practical considerations on monotherapy, combination therapy, and safety. Dermatol Clin. 2004;22: 449-459.

65. Krueger GG, Elewski B, Papp K, et al. Patients with psoriasis respond to continuous open-label etanercept treatment after initial incomplete response in a randomized, placebo-controlled trial. J Am Acad Dermatol. 2006;54:S112-119.

66. Moore A, Gordon KB, Kang S, et al. A randomized, open-label trial of continuous versus interrupted etanercept therapy in the treatment of psoriasis. J Am Acad Dermatol. 2007;56:598-603.

67. Papp KA, Tyring S, Lahfa M, et al. A global phase III randomized controlled trial of etanercept in psoriasis:safety, efficacy, and effect of dose reduction. Br J Dermatol. 2005;152:1304-1312.

68. Tyring S, Gottlieb A, Papp K, et al. Etanercept and clinical outcomes, fatigue, and depression in psoriasis:double-blind placebo-controlled randomised phase III trial. Lancet. 2006;367:29-35.

69. Gisondi P, Del Giglio M, Cotena C, et al. Combining etanercept and acitretin in the therapy of chronic plaque psoriasis:a. 24-week, randomized, controlled, investigator-blinded pilot trial. Br J Dermatol. 2008;158:1345-1349.
70. Zachariae C, Mork NJ, Reunala T, et al. The combination of etanercept and methotrexate increases the effectiveness of treatment in active psoriasis despite inadequate effect of methotrexate therapy. Acta Derm Venereol. 2008;88:495-501.

71. Klareskog L, van der Heijde D, de Jager JP, et al. Therapeutic effect of the combination of etanercept and methotrexate compared with each treatment alone in patients with rheumatoid arthritis:double-blind randomised controlled trial. Lancet. 2004;363:675-681.

72. Cohen JD, Zaltni S, Kaiser MJ, et al. Secondary addition of methotrexate to partial responders to etanercept alone is effective in severe rheumatoid arthritis. Ann Rheum Dis. 2004;63:209-210.

73. Paller AS, Siegfried EC, Langley RG, et al. Etanercept treatment for children and adolescents with plaque psoriasis. $N$ Engl J Med. 2008;358:241-251.

74. Reich K, Nestle FO, Papp K, et al. Infliximab induction and maintenance therapy for moderate-to-severe psoriasis:a phase III, multicentre, double-blind trial. Lancet. 2005;366:1367-1374.

75. Menter A, Feldman SR, Weinstein GD, et al. A randomized comparison of continuous vs. intermittent infliximab maintenance regimens over. 1 year in the treatment of moderate-to-severe plaque psoriasis. $\mathrm{J} \mathrm{Am}$ Acad Dermatol. 2007;56:31 e1-15.

76. Reich K, Nestle FO, Papp K, et al. Improvement in quality of life with infliximab induction and maintenance therapy in patients with moderate-to-severe psoriasis:a randomized controlled trial. $\mathrm{Br} J$ Dermatol. 2006;154:1161-1168.

77. Reich K, Nestle FO, Wu Y, et al. Infliximab treatment improves productivity among patients with moderate-to-severe psoriasis. Eur J Dermatol. 2007;17:381-386.

78. Menter A, Tyring SK, Gordon K, et al. Adalimumab therapy for moderate to severe psoriasis:A randomized, controlled phase III trial. J Am Acad Dermatol. 2008;58:106-115.

79. Gordon KB, Langley RG, Leonardi C, et al. Clinical response to adalimumab treatment in patients with moderate to severe psoriasis: double-blind, randomized controlled trial and open-label extension study. J Am Acad Dermatol. 2006;55:598-606.

80. Revicki DA, Menter A, Feldman S, et al. Adalimumab improves health-related quality of life in patients with moderate to severe plaque psoriasis compared with the United States general population norms: results from a randomized, controlled Phase III study. Health Qual Life Outcomes. 2008;6:75.

81. Schmitt J, Zhang Z, Wozel G, et al. Efficacy and tolerability of biologic and nonbiologic systemic treatments for moderate-to-severe psoriasis:meta-analysis of randomized controlled trials. Br J Dermatol. 2008; 159:513-526.

82. Gottlieb AB, Leonardi CL, Goffe BS, et al. Etanercept monotherapy in patients with psoriasis:a summary of safety, based on an integrated multistudy database. J Am Acad Dermatol. 2006;54: S92-S100.

83. Lecluse LL, Piskin G, Mekkes JR, et al. Review and expert opinion on prevention and treatment of infliximab-related infusion reactions. $\mathrm{BrJ}$ Dermatol. 2008;159:527-536.

84. Lee JH, Slifman NR, Gershon SK, et al. Life-threatening histoplasmosis complicating immunotherapy with tumor necrosis factor alpha antagonists infliximab and etanercept. Arthritis Rheum. 2002;46: $2565-2570$.

85. Slifman NR, Gershon SK, Lee JH, et al. Listeria monocytogenes infection as a complication of treatment with tumor necrosis factor alpha-neutralizing agents. Arthritis Rheum. 2003;48: 319-324.

86. Peterson JR, Hsu FC, Simkin PA, et al. Effect of tumour necrosis factor alpha antagonists on serum transaminases and viraemia in patients with rheumatoid arthritis and chronic hepatitis C infection. Ann Rheum Dis. 2003;62:1078-1082.

87. Ostuni P, Botsios C, Punzi L, et al. Hepatitis B reactivation in a chronic hepatitis B surface antigen carrier with rheumatoid arthritis treated with infliximab and low dose methotrexate. Ann Rheum Dis. 2003;62:686-687. 
88. Lok AS, McMahon BJ. Chronic hepatitis B. Hepatology. 2007;45: 507-539.

89. Chung SJ, Kim JK, Park MC, et al. Reactivation of hepatitis B viral infection in inactive HBsAg carriers following anti-tumor necrosis factor-alpha therapy. $J$ Rheumatol. 2009;36:2416-2420.

90. Gardam MA, Keystone EC, Menzies R, et al. Anti-tumour necrosis factor agents and tuberculosis risk:mechanisms of action and clinical management. Lancet Infect Dis. 2003;3:148-155.

91. Lim WS, Powell RJ, Johnston ID. Tuberculosis and treatment with infliximab. $N$ Engl J Med. 2002;346:623-626.

92. Keane J, Gershon S, Wise RP, et al. Tuberculosis associated with infliximab, a tumor necrosis factor alpha-neutralizing agent. $N$ Engl J Med. 2001;345:1098-1104.

93. Domm S, Cinatl J, Mrowietz U. The impact of treatment with tumour necrosis factor-alpha antagonists on the course of chronic viral infections:a review of the literature. Br J Dermatol. 2008;159:1217-1228.

94. Kwon HJ, Cote TR, Cuffe MS, et al. Case reports of heart failure after therapy with a tumor necrosis factor antagonist. Ann Intern Med. 2003;138:807-811.

95. Listing J, Strangfeld A, Kekow J, et al. Does tumor necrosis factor alpha inhibition promote or prevent heart failure in patients with rheumatoid arthritis? Arthritis Rheum. 2008;58:667-677.

96. Shakoor N, Michalska M, Harris CA, et al. Drug-induced systemic lupus erythematosus associated with etanercept therapy. Lancet. 2002;359:579-580.

97. Norman R, Greenberg RG, Jackson JM. Case reports of etanercept in inflammatory dermatoses. J Am Acad Dermatol. 2006;54:S139-S142.

98. Geborek P, Bladstrom A, Turesson C, et al. Tumour necrosis factor blockers do not increase overall tumour risk in patients with rheumatoid arthritis, but may be associated with an increased risk of lymphomas. Ann Rheum Dis. 2005;64:699-703.

99. Askling J, Fored CM, Brandt L, et al. Risks of solid cancers in patients with rheumatoid arthritis and after treatment with tumour necrosis factor antagonists. Ann Rheum Dis. 2005;64: 1421-1426.

100. Bongartz T, Sutton AJ, Sweeting MJ, et al. Anti-TNF antibody therapy in rheumatoid arthritis and the risk of serious infections and malignancies:systematic review and meta-analysis of rare harmful effects in randomized controlled trials. JAMA. 2006;295: 2275-2285.

101. Zink A, Askling J, Dixon WG, et al. European biologicals registers: methodology, selected results and perspectives. Ann Rheum Dis. 2009;68:1240-1246.

102. Nannini C, Cantini F, Niccoli L, et al. Single-center series and systematic review of randomized controlled trials of malignancies in patients with rheumatoid arthritis, psoriatic arthritis, and ankylosing spondylitis receiving anti-tumor necrosis factor alpha therapy:is there a need for more comprehensive screening procedures? Arthritis Rheum. 2009;61:801-812.

103. Lebwohl M, Blum R, Berkowitz E, et al. No evidence for increased risk of cutaneous squamous cell carcinoma in patients with rheumatoid arthritis receiving etanercept for up to 5 years. Arch Dermatol. 2005;141:861-864.

104. Wolfe F, Michaud K. Biologic treatment of rheumatoid arthritis and the risk of malignancy:analyses from a large US observational study. Arthritis Rheum. 2007;56:2886-2895.

105. Ellis CN, Krueger GG. Treatment of chronic plaque psoriasis by selective targeting of memory effector T lymphocytes. N Engl J Med. 2001;345:248-255.

106. Krueger GG. Clinical response to alefacept:results of a phase 3 study of intravenous administration of alefacept in patients with chronic plaque psoriasis. J Eur Acad Dermatol Venereol. 2003;17 Suppl 2: $17-24$.

107. Krueger GG, Papp KA, Stough DB, et al. A randomized, double-blind, placebo-controlled phase III study evaluating efficacy and tolerability of. 2 courses of alefacept in patients with chronic plaque psoriasis. J Am Acad Dermatol. 2002;47:821-833.
108. Lebwohl M, Christophers E, Langley R, et al. An international, randomized, double-blind, placebo-controlled phase 3 trial of intramuscular alefacept in patients with chronic plaque psoriasis. Arch Dermatol. 2003;139:719-727.

109. Mease PJ, Gladman DD, Keystone EC. Alefacept in combination with methotrexate for the treatment of psoriatic arthritis:results of a randomized, double-blind, placebo-controlled study. Arthritis Rheum. 2006;54:1638-1645.

110. Lebwohl M, Tyring SK, Hamilton TK, et al. A novel targeted T-cell modulator, efalizumab, for plaque psoriasis. $N$ Engl $J$ Med. 2003;349:2004-2013.

111. Joshi A, Bauer R, Kuebler P, et al. An overview of the pharmacokinetics and pharmacodynamics of efalizumab:a monoclonal antibody approved for use in psoriasis. J Clin Pharmacol. 2006;46: $10-20$.

112. Guttman-Yassky E, Vugmeyster Y, Lowes MA, et al. Blockade of CD11a by efalizumab in psoriasis patients induces a unique state of T-cell hyporesponsiveness. J Invest Dermatol. 2008;128: 1182-1191.

113. Ortonne JP, Shear N, Shumack S, et al. Impact of efalizumab on patient-reported outcomes in high-need psoriasis patients:results of the international, randomized, placebo-controlled Phase III Clinical Experience Acquired with Raptiva (CLEAR) trial [NCT00256139]. BMC Dermatol. 2005;5:13.

114. Dubertret L, Sterry W, Bos JD, et al. CLinical experience acquired with the efalizumab (Raptiva) (CLEAR) trial in patients with moderate-to-severe plaque psoriasis:results from a phase III international randomized, placebo-controlled trial. Br J Dermatol. 2006;155:170-181.

115. Leonardi CL, Papp KA, Gordon KB, et al. Extended efalizumab therapy improves chronic plaque psoriasis:results from a randomized phase III trial. J Am Acad Dermatol. 2005;52:425-433.

116. Papp KA, Bressinck R, Fretzin S, et al. Safety of efalizumab in adults with chronic moderate to severe plaque psoriasis:a phase IIIb, randomized, controlled trial. Int J Dermatol. 2006;45:605-614.

117. Pariser DM, Gordon KB, Papp KA, et al. Clinical efficacy of efalizumab in patients with chronic plaque psoriasis:results from three randomized placebo-controlled Phase III trials:part I. J Cutan Med Surg. 2005;9:303-312.

118. Papp KA, Caro I, Leung HM, et al. Efalizumab for the treatment of psoriatic arthritis. J Cutan Med Surg. 2007;11:57-66.

119. Pugashetti R, Koo J. Efalizumab discontinuation:a practical strategy. J Dermatolog Treat. 2009;20:132-136.

120. Major EO. Progressive Multifocal Leukoencephalopathy in Patients on Immunomodulatory Therapies. Annu Rev Med. 2010;61:35-47.

121. Robertson MJ, Ritz J. Interleukin. 12:Basic Biology and Potential Applications in Cancer Treatment. Oncologist. 1996;1:88-97.

122. Miossec P, Korn T, Kuchroo VK. Interleukin-17 and type. 17 helper T cells. N Engl J Med. 2009;361:888-898.

123. Blauvelt A. T-helper. 17 cells in psoriatic plaques and additional genetic links between IL-23 and psoriasis. J Invest Dermatol. 2008;128: 1064-107.

124. Krueger GG, Langley RG, Leonardi C, et al. A human interleukin12/23 monoclonal antibody for the treatment of psoriasis. $N$ Engl $J$ Med. 2007;356:580-592.

125. Leonardi CL, Kimball AB, Papp KA, et al. Efficacy and safety of ustekinumab, a human interleukin-12/23 monoclonal antibody, in patients with psoriasis:76-week results from a randomised, double-blind, placebocontrolled trial (PHOENIX. 1). Lancet. 2008;371: 1665-1674.

126. Papp KA, Langley RG, Lebwohl M, et al. Efficacy and safety of ustekinumab, a human interleukin-12/23 monoclonal antibody, in patients with psoriasis:52-week results from a randomised, double-blind, placebocontrolled trial (PHOENIX. 2). Lancet. 2008;371: 1675-1684.

127. Gottlieb A, Menter A, Mendelsohn A, et al. Ustekinumab, a human interleukin. 12/23 monoclonal antibody, for psoriatic arthritis:randomised, double-blind, placebo-controlled, crossover trial. Lancet. 2009;373:633-640. 
128. Dixon WG, Watson K, Lunt M, et al. Rates of serious infection, including site-specific and bacterial intracellular infection, in rheumatoid arthritis patients receiving anti-tumor necrosis factor therapy:results from the British Society for Rheumatology Biologics Register. Arthritis Rheum. 2006;54:2368-2376.

129. Dixon WG, Watson KD, Lunt M, et al. Reduction in the incidence of myocardial infarction in patients with rheumatoid arthritis who respond to anti-tumor necrosis factor alpha therapy:results from the British Society for Rheumatology Biologics Register. Arthritis Rheum. 2007;56:2905-2912.

130. Hyrich KL, Symmons DP, Watson KD, et al. Pregnancy outcome in women who were exposed to anti-tumor necrosis factor agents: results from a national population register. Arthritis Rheum. 2006;54: 2701-2702.

131. Choy EH, Hazleman B, Smith M, et al. Efficacy of a novel PEGylated humanized anti-TNF fragment (CDP870) in patients with rheumatoid arthritis:a phase II double-blinded, randomized, dose-escalating trial. Rheumatology (Oxford). 2002;41:1133-1137.

132. Melmed GY, Targan SR, Yasothan U, et al. Certolizumab pegol. Nat Rev Drug Discov. 2008;7:641-642.

133. Gladman D, Kavanaugh, A, McInnes, I, et al. Golimumab, a new human TNF-alpha antibody, administered every 4 weeks as a subcutaneous injection in psoriatic arthritis:Nail, enthesitis, and dactylitis response in the randomized, placebo controlled, GO-REVEAL study. (Abstract) Ann Rheum Dis. 2008;67(Suppl II).

134. Kimball AB, Gordon KB, Langley RG, et al. Safety and efficacy of ABT-874, a fully human interleukin. 12/23 monoclonal antibody, in the treatment of moderate to severe chronic plaque psoriasis:results of a randomized, placebo-controlled, phase. 2 trial. Arch Dermatol. 2008;144:200-207.
135. Zheng Y, Danilenko DM, Valdez P, et al. Interleukin-22, a $\mathrm{T}(\mathrm{H}) 17$ cytokine, mediates IL-23-induced dermal inflammation and acanthosis. Nature. 2007;445:648-651.

136. Nestle FO, Kaplan DH, Barker J. Psoriasis. N Engl J Med. 2009; 361:496-509.

137. Zaba LC, Suarez-Farinas M, Fuentes-Duculan J, et al. Effective treatment of psoriasis with etanercept is linked to suppression of IL-17 signaling, not immediate response TNF genes. J Allergy Clin Immunol. 2009;12495:1022-10, e1-395.

138. Abdelnoor AM. Patented small molecules against psoriasis. Expert Opin Ther Pat. 2009;19:1057-1071.

139. Papp K, Bissonnette R, Rosoph L, et al. Efficacy of ISA247 in plaque psoriasis:a randomised, multicentre, double-blind, placebo-controlled phase III study. Lancet. 2008;371:1337-1342.

140. Borie DC, O'Shea JJ, Changelian PS. JAK3 inhibition, a viable new modality of immunosuppression for solid organ transplants. Trends Mol Med. 2004;10:532-541.

141. Bhagwat SS. Kinase inhibitors for the treatment of inflammatory and autoimmune disorders. Purinergic Signal. 2009;5:107-115.

142. Boy MG, Wang C, Wilkinson BE, et al. Double-blind, placebo-controlled, dose-escalation study to evaluate the pharmacologic effect of CP-690,550 in patients with psoriasis. J Invest Dermatol. 2009;129:2299-2302.
Clinical, Cosmetic and Investigational Dermatology

\section{Publish your work in this journal}

Clinical, Cosmetic and Investigational Dermatology is an international, peer-reviewed, open access, online journal that focuses on the latest clinical and experimental research in all aspects of skin disease and cosmetic interventions. All areas of dermatology will be covered; contributions will be welcomed from all clinicians and

\section{Dovepress}

basic science researchers globally. This journal is indexed on CAS. The manuscript management system is completely online and includes a very quick and fair peer-review system, which is all easy to use. Visit http://www.dovepress.com/testimonials.php to read real quotes from published authors. 